\title{
Barriers of Telemedicine: Perspectives of Administrators
}

\author{
Ahmad Azizi1 ${ }^{\oplus}$, Zahra Sharifat $^{*}$
}

1- Department of Health Technology/Information Management, School of Allied Health Professions, Ahvaz University of Medical Sciences, Ahvaz-Iran

\begin{abstract}
Introduction: Telemedicine can help to provide better medical services to remote areas, provide integration of patient records and reduce the cost of health care services. Significant factors involved in the implementation of this technology that are important. This study addressed the barriers to telemedicine from perspectives of the Administrators.

Material and Methods: This study was a cross-sectional descriptive study that conducted in 1393. Because of the population was limited so sampling was not necessary. Data collection tool was check list and data were collected through interviews with the population under study. Finally, data were analyzed using SPSS software.

Results: The findings showed that organizational barriers had highest score (31.68\%) from between exist barriers to implementation of telemedicine. Then the human barriers in terms of respondents were the most important barriers. Technical barriers also were identified as the primary barriers.

Conclusion: Considering organizational factors and the development of strategic plans and planning to implement the telemedicine can bring more successfully in the implementation. The development of telecommunications infrastructure and raising awareness about the benefits of telemedicine, also may contribute to the development of this technology in hospitals.
\end{abstract}

(i) Please cite this article as:

Azizi A, Sharifat Z. Barriers of telemedicine: Perspectives of administrators. Iran J Med Inform. 2017; 6(1): 23-27. DOI: 10.24200/ijmi.v6i1.92

Article History

Received: 2016-08-11

Revised: 2017-01-19

Accepted: 2017-05-10

Published: 2017-08-15

\section{Keywords:}

Telemedicine

Telecommunication Implementation

\footnotetext{
" Corresponding Author: Z Sharifat, Department of Health Technology/Information Management, Ahvaz University of Medical Sciences, Ahvaz, Iran (Email: sharifatzahra@yahoo.com) 


\section{INTRODUCTION}

The application of information technology in the field of health care, improve life goals, better and faster service delivery and access to health information at any time and in any place [1]. One area that more affected by information technology and has been further growth, is telemedicine [2]. Telemedicine is the use of telecommunication and information technologies in order to provide clinical health care at a distance or is the ability to provide interactive healthcare utilizing modern technology and telecommunications. Development of telemedicine was since the birth of communication means, such as telegraph and telephone. Gradually telemedicine grew in different fields and regions and main reason was related to the advantages it could bring [1, 3] such as:

- $\quad$ Providing more and better medical services for remote areas, as well as forests, mountains, sea, air and space.

- Providing more and better medical services for people who are difficult or impossible to move.

- Providing medical services in the disasters in order to reduce patient transfers.

- $\quad$ Reduce health care costs and improve the quality of care and educational services.

- $\quad$ Provide integrated patient records

- And much more advantages [1, 4].

Telemedicine in Iran can be discussed and explored in several perspectives, including type of relationships between the audiences and type of activities and needed facilities. Implementation of telemedicine for care and examination of pregnant women in order to reduce maternal mortality in Isfahan and Kerman provinces have been reasonably successful results $[5,6]$.

Although the telemedicine advantages are very important and telemedicine reduce many health care problems such as the lack of health care professionals and costs, but its widespread use would be limited because of barriers. In some sources these barriers are classified in four areas: technological, organizational, human and economic spheres. In the other studies, barriers are discussed regardless of any classification [7].

Telemedicine technological issues can be classified into telecommunications, audio and video technology and network. Lack of or failure to perform any of these technological components can create barriers that reduce the usage rate of telemedicine, thus addressing these barriers is important [8]. Many telemedicine equipment need for faster connections than telephone lines [9]. The organizational environment is often crucial in determining whether or not telemedicine applications will be successful.

Identifying these barriers and create solutions for implementation of such technologies could be very helpful. Human and economic barriers have crucial role in the promotion of telemedicine [7]. In the recent years, there has been an increasing amount of literatures on telemedicine barriers and limitations. Paul et al. demonstrated that technological limitations are related to lack of basic tools and equipment in order to communication and work with information, less use of the Internet and lack of necessary standards [9]. Haghighi et al. indicated that important barriers of implementation of telemedicine are including lack of technical staff, insurance and reimbursement problems, initial costs, running costs and lack of medical staff [10].

As mentioned above, limitations and barriers could have negative affect on telemedicine adoption. Determine barriers priorities and more accurate assessments on health care organizations help both to promotion of the health system and to remove the barriers of implementation phase. Otherwise achieving to this vital technology to be delayed. It should me mentioned that Khuzestan province considered as a plain, flat and uncomplicated region, which providing services via telemedicine in this province could be easier. But now just the Internet is available in hospitals and other infrastructures have not been achieved yet. So, the aim of this study was assessing the barriers of implementation of telemedicine in the Jundishapur University of medical sciences.

\section{MATERIALS AND METHOD}

This cross-sectional descriptive study was conducted in the 2014. The study population consisted of decision-makers and managers of the university, including:

- University deputies (educational, research and treatment deputies),

- $\quad$ Authorities of faculty of medicine and directors of the clinical groups,

- Authorities of faculty of dentistry and faculty of rehabilitation.

- And the authority of statistics and information technology office.

Data collection instrument was a checklist which has been prepared based on relevant studies, sources and documents. The checklist consisted of four parts that covered major telemedicine barriers, including human, organizational, technical and financial aspects. Generally, it had 26 options. Likert five options scale was employed. Content Validity also was confirmed. Data were collected by face to face interview with the directors. Data analysis was performed using descriptive statistic (mean and frequency) with SPSS and Excel software.

\section{RESULT}

A total of 26 filled checklist was obtained. All of interviewed persons were male and the mean age of them was 45-55 years. Data collection was done during 3 months and collaboration of population was not very good.

Scores of each category were analyzed separately. The results obtained from the preliminary data analysis are shown in Fig 1.

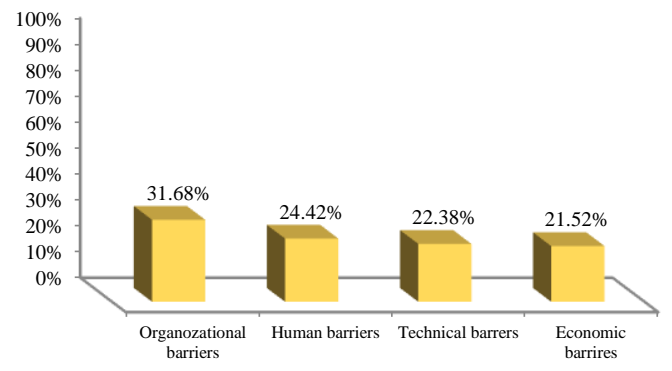

Fig 1: Percentage scores obtained by groups of barriers present

As it shown in Fig 1, organizational barriers have most important role in telemedicine implementation. All the respondents had a strong emphasis on organizational barriers. They mentioned that such barriers could be considered as the most important barriers of telemedicine implementation. These barriers include nonacceptance of changes in the health care model, lack of strategic plan, imperfect management of project and lack of insurance coverage and reimbursement. More than $80 \%$ of respondents stated that lack of strategic planning is so important (Table 1). They noted that it should be done first of all, then the project could be properly implemented and followed. Therefore, project management is one of the most important factors imperfect management is a significant risk. 
Table 1: Percentage of respondents to organizational barriers

\begin{tabular}{|l|l|l|l|l|l|l|}
\hline Subset & $\begin{array}{l}\text { Strongly } \\
\text { barrier }\end{array}$ & $\begin{array}{l}\text { Less Strongly } \\
\text { barrier }\end{array}$ & $\begin{array}{l}\text { Important } \\
\text { barrier }\end{array}$ & $\begin{array}{l}\text { Initial } \\
\text { barrier }\end{array}$ & $\begin{array}{l}\text { Sum } \\
\text { scores }\end{array}$ & $\begin{array}{l}\text { Std. } \\
\text { Deviation }\end{array}$ \\
\hline $\begin{array}{l}\text { Non acceptance of changes in } \\
\text { the health care model }\end{array}$ & $34.6 \%$ & $3.8 \%$ & $30.8 \%$ & 30.8 & 89 & 1.27 \\
\hline Lack of strategic planning & $80.8 \%$ & $7.7 \%$ & $7.7 \%$ & $3.8 \%$ & 121 & .797 \\
\hline $\begin{array}{l}\text { Imperfect management of } \\
\text { project }\end{array}$ & $61.5 \%$ & $23.1 \%$ & $11.5 \%$ & $3.8 \%$ & 115 & .857 \\
\hline $\begin{array}{l}\text { Lack of insurance coverage } \\
\text { and reimbursement }\end{array}$ & $61.5 \%$ & $15.4 \%$ & $15.4 \%$ & $7.65 \%$ & 111 & 1.116 \\
\hline
\end{tabular}

The second category of barriers was human factors. According to Fig 1 , it falls into the second rank of importance. The results showed in Table 2. Respondents are considered on "Responsibility for malpractice" as the most important human factor. Other factors have also high score.

The third category was the economic barriers. Among the factors, "Equipment cost" is far more important than others (Table 3).

Table 2: Percentage of respondents to human barriers

\begin{tabular}{|l|l|l|l|l|l|l|l|}
\hline Subset & $\begin{array}{l}\text { Strongly } \\
\text { barrier }\end{array}$ & $\begin{array}{l}\text { Less } \\
\text { Strongly } \\
\text { barrier }\end{array}$ & $\begin{array}{l}\text { Important } \\
\text { barrier }\end{array}$ & $\begin{array}{l}\text { Initial } \\
\text { barrier }\end{array}$ & $\begin{array}{l}\text { No } \\
\text { barrier }\end{array}$ & $\begin{array}{l}\text { Sum } \\
\text { scores }\end{array}$ & Std. Deviation \\
\hline Lack of confidence & $30.8 \%$ & $7.7 \%$ & $34.6 \%$ & $7.7 \%$ & $19.2 \%$ & 84 & 1.478 \\
\hline $\begin{array}{l}\text { Less knowledge of } \\
\text { health field managers } \\
\text { and experts }\end{array}$ & $11.5 \%$ & $53.8 \%$ & $7.7 \%$ & $7.7 \%$ & $19.2 \%$ & 86 & 1.35 \\
\hline $\begin{array}{l}\text { Cultural and ethical } \\
\text { challenges }\end{array}$ & $26.9 \%$ & $3.8 \%$ & $11.5 \%$ & $19.2 \%$ & $38.5 \%$ & 68 & 1.675 \\
\hline $\begin{array}{l}\text { Lack of patient } \\
\text { knowledge }\end{array}$ & $46.2 \%$ & $7.7 \%$ & $3.8 \%$ & $11.5 \%$ & $30.8 \%$ & 85 & 1.823 \\
\hline Employee resistance & $34.6 \%$ & $15.4 \%$ & $7.7 \%$ & $23.1 \%$ & $19.2 \%$ & 84 & 1.608 \\
\hline Licensing problems & $7.7 \%$ & $11.5 \%$ & $42.3 \%$ & $19.2 \%$ & $19.2 \%$ & 70 & 1.158 \\
\hline Malpractice liability & $42.3 \%$ & $11.5 \%$ & $23.1 \%$ & $3.8 \%$ & $19.2 \%$ & 92 & 1.155 \\
\hline $\begin{array}{l}\text { Lack of training for } \\
\text { health care workers }\end{array}$ & $11.5 \%$ & $19.2 \%$ & $42.3 \%$ & $23.1 \%$ & $3.8 \%$ & 81 & 1 \\
\hline Lack of technical staff & $38.5 \%$ & $11.5 \%$ & $26.9 \%$ & $15.4 \%$ & $7.7 \%$ & 93 & 1.362 \\
\hline
\end{tabular}

Table 3: Percentage of respondents to economic barriers

\begin{tabular}{|l|l|l|l|l|l|l|l|}
\hline Subset & $\begin{array}{l}\text { Strongly } \\
\text { barrier }\end{array}$ & $\begin{array}{l}\text { Less } \\
\text { Strongly } \\
\text { barrier }\end{array}$ & $\begin{array}{l}\text { Important } \\
\text { barrier }\end{array}$ & $\begin{array}{l}\text { Initial } \\
\text { barrier }\end{array}$ & $\begin{array}{l}\text { No } \\
\text { barrier }\end{array}$ & $\begin{array}{l}\text { Sum } \\
\text { scores }\end{array}$ & $\begin{array}{l}\text { Std. } \\
\text { Deviation }\end{array}$ \\
\hline Equipment costs & $46.2 \%$ & $3.8 \%$ & $19.2 \%$ & $30.8 \%$ & 0 & 82 & 1.84 \\
\hline Software costs & $42.3 \%$ & $7.7 \%$ & $19.2 \%$ & $30.8 \%$ & 0 & 81 & 1.81 \\
\hline Current cost & $11.5 \%$ & $19.2 \%$ & $7.7 \%$ & $30.8 \%$ & $30.8 \%$ & 65 & 1.42 \\
\hline Cost of staff training & $19.2 \%$ & 0 & $11.5 \%$ & $57.7 \%$ & $11.5 \%$ & 67 & 1.30 \\
\hline
\end{tabular}

The fourth category was technical barriers (Table 4). Respondents know this category as the primary and dynamic barrier. They pointed out that in comparison with other factors, this is less important and with adequate funding, this problem will be resolve in the first stage. However, in turn, it plays an important role in telemedicine implementation.

\section{DISCUSSION}

Different studies noted various barriers for the implementation of telemedicine. This study listed them in four categories and studied in the field of Jundishapur University of medical sciences. The results of this study showed that organizational barriers are more important in telemedicine adoption and implementation. The decision for implementation of telemedicine should be taken at high levels. The primary problem in this category was lack of attention and non-introduction of telemedicine in the organizations. Currently in Jundishapur University, there are no plan to adopt telemedicine. So, it can be concluded that implementation of telemedicine, takes a long time. Respondents expressed that without high-level planning, discussion about other aspects of telemedicine implementation is meaningless. Another important issue in the organizational debate was insurance and reimbursement.

Currently no insurance organization (governmental or nongovernmental) cover telemedicine services. This is especially important for physicians. Need to serious approaches suggested and followed by experts in this field. LeRouge and Garfield in their study indicated that the reimbursement situation is somewhat recursive in that additional financial data are needed to provide evidence to insurance companies that telemedicine provides a financial benefit in reducing the higher costs of medical care. They also noted that insurance companies such as Medicare and Medicaid will be expanding telemedicine coverage [11]. 
The second category of the barriers was human barriers. Respondents stated that this category plays an important role in terms of implementation of telemedicine that should be seriously followed. Two important subsets was including lack of technical staff and malpractice liability. Other subsets were lack of confidence to telemedicine.

Table 4: Percentage of respondents to Technical barriers and subsets

\begin{tabular}{|c|c|c|c|c|c|c|c|}
\hline Subset & $\begin{array}{l}\text { Strongly } \\
\text { barrier }\end{array}$ & $\begin{array}{l}\text { Less } \\
\text { Strongly } \\
\text { barrier }\end{array}$ & $\begin{array}{l}\text { Important } \\
\text { barrier }\end{array}$ & $\begin{array}{l}\text { Initial } \\
\text { barrier }\end{array}$ & $\begin{array}{l}\text { No } \\
\text { barrier }\end{array}$ & $\begin{array}{l}\text { Sum } \\
\text { scores }\end{array}$ & $\begin{array}{l}\text { Std. } \\
\text { Deviation }\end{array}$ \\
\hline $\begin{array}{l}\text { Lack of network with more than } 10 \\
\text { MB broadband }\end{array}$ & $38.5 \%$ & $11.5 \%$ & $15.4 \%$ & $19.2 \%$ & $15.4 \%$ & 88 & 1.551 \\
\hline Security limitations & $3.8 \%$ & $7.7 \%$ & $19.2 \%$ & $19.2 \%$ & $50 \%$ & 51 & 1.183 \\
\hline Privacy issues & $26.9 \%$ & $7.7 \%$ & $3.8 \%$ & $30.8 \%$ & $30.8 \%$ & 70 & 1.644 \\
\hline $\begin{array}{l}\text { Lack of necessary standards for } \\
\text { implementation }\end{array}$ & $53.8 \%$ & 7.75 & $7.7 \%$ & $3.8 \%$ & $26.9 \%$ & 93 & 1.77 \\
\hline $\begin{array}{l}\text { Lack of telecommunications } \\
\text { network such as satellite }\end{array}$ & $53.8 \%$ & $7.7 \%$ & $3.8 \%$ & $7.7 \%$ & $26.9 \%$ & 92 & 1.794 \\
\hline $\begin{array}{l}\text { Lack of equipment to conversion } \\
\text { non-digital information to digital }\end{array}$ & $19.2 \%$ & $11.5 \%$ & $38.5 \%$ & $3.8 \%$ & $26.9 \%$ & 76 & 1.44 \\
\hline Lack of digital medical equipment & $26.9 \%$ & $3.8 \%$ & $38.5 \%$ & $3.8 \%$ & $26.9 \%$ & 78 & 1.523 \\
\hline $\begin{array}{l}\text { The lack of computer equipment } \\
\text { equipped with digital video } \\
\text { recorder }\end{array}$ & $38.5 \%$ & $3.8 \%$ & $11.5 \%$ & $19.2 \%$ & $26.9 \%$ & 80 & 1.719 \\
\hline $\begin{array}{l}\text { Lack of storage equipment and } \\
\text { digital display information }\end{array}$ & $23.1 \%$ & $23.1 \%$ & $11.5 \%$ & $11.5 \%$ & $30.8 \%$ & 77 & 1.612 \\
\hline
\end{tabular}

It should be mentioned that with the arrival of technology, initially little resistance will be created because of the lack of confidence. The solution is that the users informed about benefits of technology and teach them how to use and make sure they have learned. On the implementation of technology in hospitals, administrative team should not be to release users and abandon them with technology. But they should proceed step by step with them as long as the technology to be in a good place.

Lack of knowledge of experts and physicians about the applications of telemedicine and where this technology is necessary to be used, will leads to not good understanding about telemedicine, so always ask this question: "why do need to use telemedicine? Will this method of treatment reach to favorable results?"

Respondents stated "Is not it better instead of using telemedicine and purchase all costly equipment, we use our trained manpower? It may be followed less costly". Answer to this question should be targeted to further studies and future research to determine effectiveness of using human resources and purchasing telemedicine equipment. Lack of training of health care workers was another challenge. Rahimzadeh et al. were assessed the awareness and readiness of individuals about telemedicine and concluded that the awareness of experts of Imam Khomeini hospital (Ardebil city) was not enough [12]. Knowledge of experts is an important factor which has been discussed in many studies. Ludwick et al. noted that if before implementation of technology, we training staffs about its advantages, disadvantages and features, they had more incentive for use of this technology [13].

Unfortunately, introduction of telemedicine, its functions and benefits, not embedded as the courses for students and they not trained enough. They have not much opportunity to learn the basics of telemedicine, after graduation and employment in the clinical setting and even working with the simplest technologies is difficult for them. Education of using telemedicine, firstly must begin in the educational environment. Unfortunately, medical students' knowledge about telemedicine is very low. Training of medical staff about telemedicine also is important. Asadi et al. mentioned that lack of specialized human resources in information technology, initial resistance to use of information technology, lack of prior knowledge in the field of information technology, low culture level of using information technology, lack of educational programs and lack of incentives in employees as human resource management challenges in using information technology in hospitals. Corporation culture and support of human resources in this field can be a stimulating factor [14].

The next category was economic barriers. These barriers in terms of the importance are after the human and organizational barriers, although are in place more importance to themselves. The lack of initial budget allocation for implementation of telemedicine can consider a component of both organizational and economic barriers. However, we can trust this believing: "spending for telemedicine affordable because after a while, in addition to costs compensation, avail also followed" [11]. Respondents stated that technical barriers are a component of initial barriers. This means that with purchase of equipment and establishment of standards in this field, the concerns is will be resolved. Appropriate connection to the Internet in hospitals is the backbone of telemedicine. To implement high level telemedicine services, we should have broadband and high-speed connection to the Internet for transmitting of information. Medical data exchange standards such as HL7 and DICOM should be used in hospitals. Haghighi et al. found that all centers affiliated to Hormozgan University of medical sciences have the Internet access but usable broadband for users is $128 \mathrm{~KB}$. There is not also video conferencing equipment. Telecommunications infrastructure and the Internet connections (broadband) through the availability, security and cost-effectiveness affect the outcomes of telemedicine [10].

\section{CONCLUSION}

This study was simply investigated the barriers of telemedicine. It is highly recommended that future studies focus on the feasibility of telemedicine. Infrastructures also could be separately examined. Study on Telemedicine should be taken in the national level to achieve an overview. 
In addition to the barriers mentioned in this study, there are more barriers and challenges encountered the telemedicine implementation, therefore, more studies recommended to be carried out in this area.

\section{ACKNOWLEDGEMENT}

This study was founded by vice-chancellor for research affairs of Jundishapur University of medical sciences. Thanks for everyone who helped us in this study.

\section{REFERENCES}

1. Sadoghi F, Samadbeig M, Ehteshami AA, Aminpour F, Rezaei P. Health information technology. Jafari Publication: Tehran. 2011.

2. Torani S, Khammarnia M, Delgoshaei B. The ability of specialized hospitals of Iran University of medical sciences in establishing remote medical advice. Health Information Management. 2011; 8(6): 785-94.

3. $\mathrm{Hu}$ PJ-H, Chau PYK, Sheng ORL. Adoption of telemedicine technology by health care organizations: An exploratory study. Journal of Organizational Computing And Electronic Commerce. 2002; 12(3): 197-221. DOI: 10.1207/S15327744JOCE1203_01

4. Rabiei R, Ayatollahi H. Introduction to telemedicine. Morsal publication. Kashan. 2006.

5. Keshvari H, Haddadpoor A, Taheri B, Aghdak P, Nasri M. Feasibility of implementing telemedicine according to the elements of strategic planning in Isfahan University of medical sciences. Health Information Management. 2015; 12(5): 625-35.

6. Ranjbar H, Borhani F, Abbaszadeh A. Information technology application in medicine and nursing. J Qual Res Health Sci. 2010; 9 (1): 61-67.

7. Roig F, Saig F. Barriers to the normalization of telemedicine in a healthcare system model based on purchasing of healthcare services using providers' contracts. Gac Sanit. 2011; 25(5): 397-402. PMID: 21719160 DOI: 10.1016/j.gaceta.2011.01.004 [PubMed]

8. Carter B. Technology adoption in health care: International barriers and opportunities to telemedicine. Journal of Child Health Care. 2014; 18(4): 299-301. PMID: 25480032

9. Paul DL, Pearson KE, McDaniel RR. Assessing technological barriers to telemedicine: Technology management implications. Engineering Management, IEEE. 1999; 46(3): 279-88.

10. Hayavi Haghighi MH, Alipour J, Mastaneh Z, Mouseli L. Feasibility study of telemedicine implementation in Hormozgan University of medical sciences. Hormozgan Medical Journal. 2011; 15(2): 128-37.

11. LeRouge C, Garfield M. Crossing the telemedicine chasm: Have the US barriers to widespread adoption of telemedicine been significantly reduced. Int J Environ Res. Public Health. 2013; 10(12): 6472-84. PMID: 24287864 DOI: 10.3390/ijerph10126472 [PubMed]

12. Rahimzadeh A, Rahimzadeh S, Azadi S, Amani F. Establish the feasibility of using telemedicine in Imam Khomeini hospital. CADUCEUS. 2012 ; 2(2): 1-11.

13. Ludwick DA, Doucette J. Adopting electronic medical records in primary care: Lessons learned from health information systems implementation experience in seven countries. Int J
Med Inform. 2009; 78(1): 22-31. PMID: 18644745 DOI: 10.1016/j.ijmedinf.2008.06.005 [PubMed]

14. Asadi F, Mastaneh Z. Challenges of using information technology in hospitals affiliated to Shahid Beheshti University of medical sciences. Iranian Journal of Surgery. 2012; 20(1): 18-26. 